\title{
Podcast sebagai Alternatif Distribusi Konten Audio
}

\author{
Efi Fadilah ${ }^{1}$, Pandan Yudhapramesti, Nindi Aristi \\ Fakultas Ilmu Komunikasi Universitas Padjadjaran
}

\begin{abstract}
The proliferation of internet has been another warning bell for conventional broadcast radio. Numbers of listener gradually shift to the new mean of media as it is more attractive and convenient for users. The situation drives radio managers to adapt with various ways. Developing audio podcast is among the strategy that has been growing in the United States and various countries in Europe, but not yet quite popular in Indonesia. Whereas the potential audience is quite large, since the growing number of commuters and fact that about $30 \%$ of total population is categorized as auditory learner. For such reason, this library research is conducted to explore the opportunities for audio podcast to develop in Indonesia, as well as content analysis of some of the most successful podcast provider sites. The results show that audio podcast optimization strategy includes the development of podcast materials with appropriate approach and content distribution with audience's needs, wants, and ways of consuming audio content; as well as the compatibility of the content with the character and orientation of the media. In addition, this effort must also be accompanied by intensive campaigns through various way.
\end{abstract}

Keywords: audio content, audio podcast, Indonesia.

\begin{abstract}
Abstrak
Kemunculan internet membuat radio siaran konvensional merasakan ancaman ditinggalkan pendengarnya. Berbagai cara dilakukan pengelola radio siaran untuk beradaptasi dengan perubahan perilaku pendengar, khususnya dalam mengonsumsi konten audio. Salah satu strategi adalah dengan mengembangkan podcast audio. Bentuk ini cukup populer di Amerika Serikat dan berbagai negara di Eropa, bahkan menguntungkan secara bisnis, namun belum cukup populer di Indonesia. Padahal potensi khalayaknya cukup besar, karena selain dapat didengarkan di jalan oleh para komuter, sekitar $30 \%$ populasi
\end{abstract}

\footnotetext{
${ }^{1}$ Korespondensi Penulis :

Efi Fadilah, Program Studi Jurnalistik Fakultas IImu Komunikasi Universitas Padjadjaran, Jalan Raya Bandung Sumedang, KM. 21, Jatinangor, Sumedang 45363

efi.fadilah@unpad.ac.id
} 
merupakan pembelajar auditori. Untuk itulah dilakukan penelitian kepustakaan yang bertujuan untuk mengeksplorasi peluang podcast audio untuk berkembang di Indonesia, serta analisis isi terhadap beberapa situs penyedia konten podcast yang cukup sukses di Indonesia. Hasil penelitian menunjukkan bahwa strategi optimalisasi podcast audio mencakup pengembangan bahan podcast; pendekatan dan distribusi konten yang sesuai dengan kebutuhan, keinginan, serta cara khalayak mengonsumsi konten audio; serta kesesuaian konten dengan karakter dan orientasi media. Selain itu, upaya ini juga harus disertai kampanye yang intensif melalui berbagai cara.

Kata Kunci : Indonesia, konten audio, podcast audio.

\section{Pendahuluan}

Radio siaran konvensional mulai merasakan ancaman ditinggalkan pendengar setianya. Sejumlah pendengar lebih tertarik mengakses beragam konten di internet dan perlahan tapi pasti mulai berjarak dengan siaran radio konvensional. Berdasarkan hasil riset Roy Morgan tahun 2014, konsumsi radio siaran di Indonesia berada di urutan terbawah. Hanya $22 \%$ dari total populasi Indonesia mengkonsumsi radio siaran konvensional. Urutan teratas ditempati televisi, disusul internet, dan koran. Riset Nielsen pada kuartal ke 4 di tahun yang sama juga menunjukkan tren negatif dimana durasi kependengaran radio kurang dari dua jam per hari.

Grafik 1.

Prosentasi Konsumsi Media di Indonesia tahun 2014

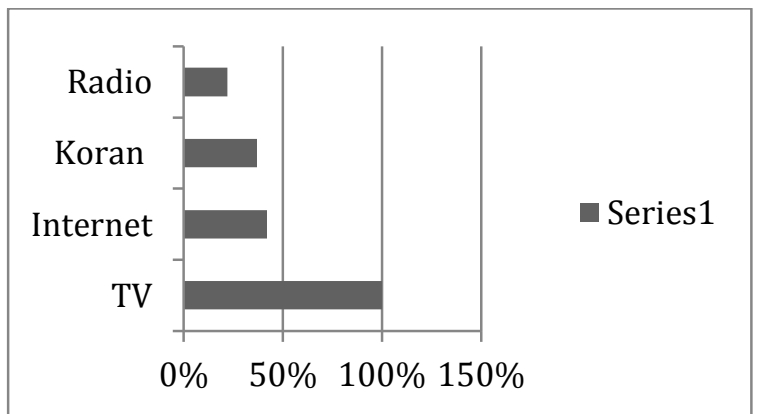

Sumber: Roy Morgan Single Source Indonesia, 2014

Bukan kali ini saja perkembangan teknologi berdampak bagi radio siaran. Di puncak masa jayanya di era 1920-an, radio menyita perhatian khalayak dan 'merebut' pembaca surat kabar. Guncangan terjadi ketika daya tarik audio visual televisi menggeser kepopuleran radio. Berikutnya kehadiran teknologi FM (frequency modulation) pada pemancaran radio menggantikan gelombang frekuensi AM (amplitudo modulation) di Amerika Serikat pada era 1940-an. Pendengar radio AM berbondong-bondong pindah mendengarkan radio di frekuensi FM yang memiliki banyak kelebihan dibanding AM, seperti lebih dinamis, suara lebih jernih, dan noise lebih rendah (Prayudha, 2005). Meski mengalami pasang naik dan pasang surut 
sepanjang perkembangannya, radio siaran tidak pernah benar-benar menghilang. Sebagaimana Fidler berpendapat bahwa kehadiran media dengan teknologi baru tidak serta merta mematikan media lama (Fidler, 2003). Radio siaran masih dapat 'hidup' asal dapat beradaptasi dengan perkembangan teknologi.

Kehadiran internet kembali membunyikan lonceng peringatan bagi keberlangsungan radio siaran. Rhoads mengingatkan para pengelola radio siaran kembali bersiap menghadapi perpindahan pendengar radio ke internet (Rhoads, 2003). Meski demikian, internet tidak semata menjadi ancaman, akan tetapi pada saat bersamaan juga menyediakan peluang untuk dimanfaatkan pada pengelola radio siaran.

Format audio sebagai basis konten radio dapat menempati 'ruang' di internet. Sebuah hasil riset yang dirilis awal tahun 2016 oleh Reuters Institute yang berjudul "Media, Journalism, and Technology Prediction" menyebutkan bahwa internet memungkinkan format audio untuk bangkit kembali,

"While video continues to lead the way, audio is undergoing a revival driven by connected smartphones and its multitasking friendly format. In the US, Barack Obama made his podcast debut on WTF with Marc Maron and Serial announced an exclusive distribution deal for its second series through Pandora."

Di Dunia Maya, radio online ataupun situs radio cukup marak. Umumnya radio siaran konvensional memiliki situs online di internet. Memang belum semua situs tersebut dikelola optimal. Namun, situs online radio Indonesia seperti www.prfm.com dan www.suarasurabaya.com berkembang cukup baik. Sementara di Amerika Serikat, akses terhadap radio online cenderung meningkat dari tahun ke tahun. Menurut hasil survei Edison Research yang dirilis PEW Research Centre, jumlah pengakses radio online 2015 naik ke angka 53\% di banding jumlah pengakses di tahun 2010 yang tercatat berada di posisi $27 \%$. Umumnya pengakses (73\%) menggunakan telepon pintar (smartphone) untuk mendengarkan radio online. Pertumbuhan pendengar radio online juga ditunjukkan lewat peningkatan jumlah pemilik telepon seluler yang mendengarkan radio online di dalam mobil. Tren akses dengan cara seperti ini naik enam kali lipat di tahun 2015 (35\%) dibanding hanya 6\% di tahun 2010 (Grafik 2.).

Konten audio yang merupakan basis siaran radio, berpotensi untuk dikembangkan di ranah internet. Selain 'menyambungsiarkan' program melalui live streaming di situs radio online, program-program radio juga dapat didistribusikan melalui youtube, media sosial, atau secara podcast. Bentuk distribusi yang terakhir ini belum begitu populer di Indonesia. Padahal, istilah dan praktik podcast mulai dikenal antara tahun 2004-2005. Secara sederhana, podcast diartikan materi audio atau video yang tersedia di internet yang dapat secara otomatis dipindahkan ke komputer atau media pemutar portable baik secara gratis maupun berlangganan.

Grafik 2.

Peningkatan Jumlah Pendengar Radio Online di AS 


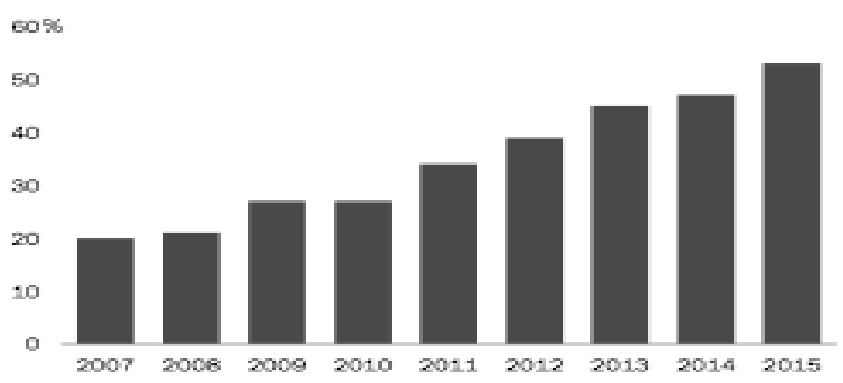

Sumber: Edison Research dalam PEW Research Center:

The State of the News Media 2015

Popularitas podcast di Amerika Serikat cenderung meningkat. Nancy Vogt dalam laporan akhir tahunan PEW Research Institute menyatakan meski diakses sekelompok kecil khalayak, namun podcast di Negeri Paman Sam semakin berkembang. Data dari Edison Research tahun 2016 menunjukkan bahwa 21\% warga Amerika usia 12 ke atas pernah mendengarkan podcast dalam 1 bulan terakhir. Data ini menunjukkan peningkatan jumlah pendengar podcast dibanding tahun 2013 yang ada pada kisaran 12\%. Bahkan persentasenya meningkat sampai $36 \%$ untuk kategori 'pernah mendengarkan podcast' yang meningkat dua kali lipat dibanding data tahun 2008 .

\section{Grafik 3.}

Peningkatan Persentase Jumlah Warga Amerika yang Mendengarkan Podcast 1 bulan terakhir

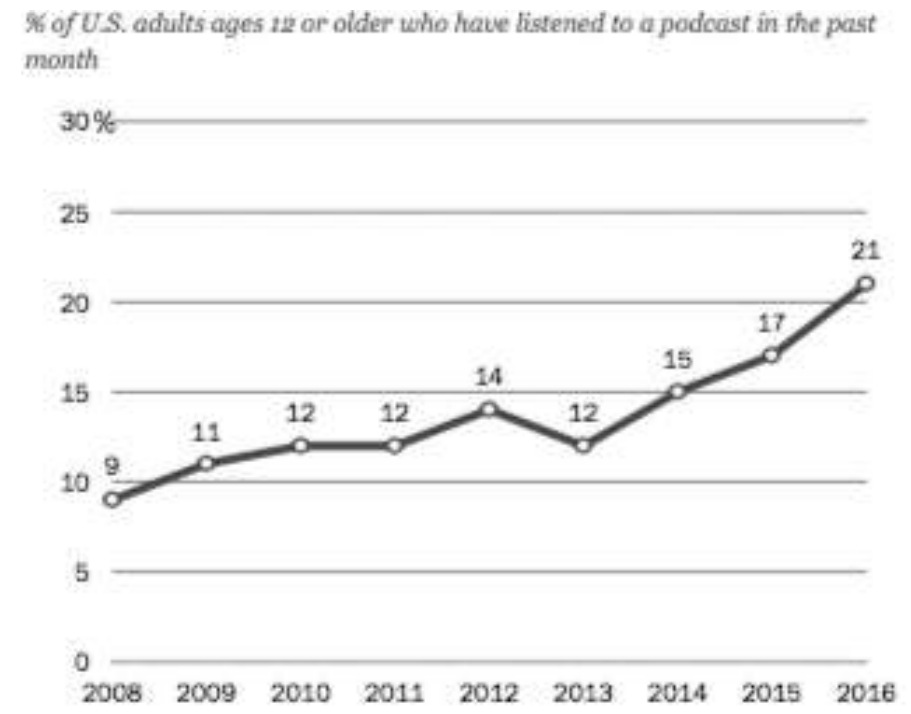

Sumber: Edison Research dalam PEW Research Center: State of the News Media 2016

Data dari Reuters Institute tahun 2016 mencatat sekitar 17 persen orang Amerika Serikat secara aktif mendengarkan podcast. Konten podcast audio tersedia cukup banyak dengan kualitas yang semakin baik. Selain itu, terdapat layanan aplikasi 
khusus yang memudahkan khalayak untuk mengakses konten podcast audio.

Podcast audio dapat menjadi peluang bagi para pengembang konten audio termasuk para pengelola radio siaran konvensional di Indonesia. Menurut Geoghegan dan Klass, potensi podcast terletak pada keunggulannya; dapat diakses secara otomatis, mudah dan kontrol ada di tangan konsumen, dapat dibawa-bawa, dan selalu tersedia (2007). Langkah pemanfaatan membutuhkan wawasan memadai sebagai referensi. Sementara itu, sejauh ini diskusi mengenai perkembangan pemanfaatan podcast di Indonesia belum begitu marak. Para peneliti media di Tanah Air juga belum banyak melakukan kajian mengenai podcast audio. Tulisan ini diharapkan bermanfaat sebagai bahan diskusi awal untuk menggali lebih jauh potensi podcast sebagai salah satu pilihan media distribusi konten audio.

Berbagai pertimbangan tersebut dirumuskan dalam penelitian ini menjadi, "Bagaimana potensi pengembangan podcast audio serta bentuk-bentuk alternatif pengembangan podcast di Indonesia?" Rumusan ini diidentifikasi lebih lanjut menjadi bagaimana model pengembangan podcast yang telah lebih dahulu populer di Amerika Serikat dan Eropa; bagaimana formula konsep konten audio yang sesuai dengan karakter target potensi khalayak konten audio di Indonesia, serta bentuk-bentuk baru konten audio podcast seperti apakah yang dapat dikembangkan untuk medium online?

\section{Kajian Pustaka}

\section{Radio, Konten Audio dan Perkembangan Teknologi Media}

Konten audio dapat dikaitkan atau tidak dikaitkan dengan karakteristik radio siaran. Karakteristik konten podcast audio memiliki sebagian gambaran karakteristik radio siaran, seperti misalnya sifatnya yang auditif dapat membangun imajinasi seseorang. Namun demikian, konten podcast audio yang dimuat di media online merupakan bagian dari medium interaktif, berbeda dengan materi siaran audio yang dimuat di radio siaran konvensional maupun radio online, yang merupakan bagian dari medium linear. Kesamaan dan perbedaan tersebut menjadikan beberapa perbedaan dalam konsep-konsep tentang permrograman atau strategi program untuk konten podcast audio dan radio siaran linear. Meski terdapat perbedaan, pemahaman tentang kedua hal tersebut merupakan hal yang penting dikuasai oleh mereka yang bergelut di bidang pengembangan konten audio maupun siaran radio.

Radio ikut berubah setiap waktu mengikuti perubahan lingkungan, budaya, teknologi, termasuk perubahan aturan dan perubahan sosial (Dubber, 2013). Menghadapi perkembangan teknologi serta perubahan karakter atau perilaku penggunaan media, radio harus dapat beradaptasi dengan medium internet. Sebagaimana dikatakan Black (2001) dalam Dubber, identitas sebuah medium sebagian berasal dari bagaimana ia diterima dan dirawat oleh para penggunanya. Mungkin saja industri memberi pengaruh terhadap karakteristik pembentukan radio. Namun apapun adanya, jika internet audio telah diperlakukan atau dianggap sebagaimana radio, maka internet audio adalah bentuk baru dari radio. 
Hal paling mendasar dari teknologi internet adalah bahwa medium tersebut dapat mengkonvergensikan berbagai bentuk pesan, baik berupa pesan teks, gambar, suara, serta video (audio visual) dan menyebarluaskannya secara langsung ataupun tertunda. Selain itu, internet memberikan kesempatan bagi siapa saja yang memiliki akses terhadapnya untuk menggunakannya secara pasif, sebagai penikmat saja, ataupun secara aktif, dengan ikut memproduksi konten yang diletakkan dalam email, website, blog, atau belakangan melalui media sosial. Internet memungkinkan terjadinya komunikasi antar banyak pihak.

Telah menjadi perdebatan panjang, apakah medium konvergensi ini merupakan ancaman bagi eksistensi medium konvensional yang berbasis tunggal seperti medium cetak (majalah atau surat kabar), medium audio (radio siaran) atau medium audio visual (televisi), atau merupakan medium tambahan yang dapat melengkapi kehadiran medium konvensional. Hingga akhir tahun 1990-an beberapa ahli seperti McQuail dan Livingstone (McQuail, 2011) masih menyebutkan internet sebagai penambahan, bukan penggantian bagi media konvensional.

Strategi pemrograman dapat dilakukan sesuai karakteristik medium dan targettarget yang hendak dicapai. Perilaku generasi baru dalam menggunakan medium internet membuat berbagai media konvensional perlu melakukan penyesuaian yang cukup radikal. Migrasi ke dunia online merupakan hal yang tidak terhindarkan. Migrasi tidak hanya menyangkut memindahkan konten kepada medium baru, seperti melakukan streaming siaran radio di internet dan menjelaskan fasilitas streaming tersebut dalam website radio siaran, namun juga harus melakukan penyesuaian produksi dan bentuk konten, navigasi applikasi yang mudah dikenali dan diakses khalayak, dan lain sebagainya.

Dalam komunitas radio online internasional, terdapat sebuah lembaga pemeringkat (Webarward), yang memberi penghargaan kepada website radio online terbaik. Seleksi didasarkan atas kriteria kualitas desain, kemudahan untuk digunakan, naskah (copywriting), interaktivitas, penggunaan teknologi, inovasi, serta konten. Terkait dengan strategi pemrograman di ranah online, Valerie Geller (2011) mengingatkan agar para penyusun program selalu menyadari karakteristik khalayak yang multitasking sehingga harus selektif memilih konten, rajin melakukan publikasi atau promosi silang di berbagai media, termasuk melakukan promosi di media sendiri, serta memastikan keamanan data dan aturan main yang jelas terkait hal yang boleh dan tidak boleh dilakukan oleh pengelola dan khalayak. Program yang betul-betul menarik dapat membuka peluang monetisasi.

\section{Asal Usul dan Pengertian Podcast}

Tahun 2004 tercatat sebagai awal kemunculan istilah podcast. Ben Hammersley menyebutkan kata "podcasting" di dalam artikelnya di www.theguardian.com yang membahas audioblogs dan radio online. Selama hampir 7 bulan, istilah "podcasting" seolah tenggelam sampai akhirnya beberapa orang menggunakannya sebagai nama pada saat mendaftarkan domain seperti yang dilakukan Dannie Gregoire yang 
mendaftarkan domain podcaster.net (Geoghegan \& Klass, 2007).

Catatan lain menyebutkan, podcast audio telah berkembang sejak tahun 2005, saat Apple menambahkan materi podcast pada iTunes dengan tema-tema terbatas. Seiring waktu, materi podcast semakin berkembang dan beragam. Kemasannya dapat berupa sandiwara/drama, dialog/talkshow, monolog dan feature/dokumenter. Ren-tang topiknya sangat luas, mulai dari sejarah, ilmu pengetahuan, politik, ekonomi, filsafat dan masih banyak lagi. Bahkan menurut www.time.com, beberapa program podcast dapat menyamai popularitas serial drama televisi.

Awalnya istilah podcast cenderung identik dengan materi berformat audio. Seperti yang tertera di dalam kamus Oxford: "a digital audio file made available on the Internet for downloading to a computer or portable media player, typically available as series, new instalments of which can be received by subscribers automatically."

Belakangan, podcast juga mengacu pada materi dalam bentuk video. Sehingga pengertian podcast dapat mengacu pada podcast audio atau podcast video. Apple sendiri membuat batasan podcast sebagai siaran audio dan video yang tersedia di internet untuk diputarkan pada perangkat portable atau komputer, seperti iPad, Ipod, atau Mac. Singkat cerita, istilah podcast diartikan sebagai materi audio atau video yang tersedia di internet yang dapat secara otomatis dipindahkan ke komputer atau media pemutar portable baik secara gratis maupun berlangganan.

\section{Cara Kerja dan Disribusi Podcast}

Produksi dan distribusi podcast tergolong sederhana. Ada 3 elemen wajib, yaitu (1) materi podcast, (2) penyedia RSS (Really Simple Syndication), dan (3) penangkap (podcatcher). Ukuran dokumen (file) berkisar antara $1 \mathrm{mb}$ sampai $200 \mathrm{mb}$ (tergantung dari frame rate, ukuran dsb.). Elemen berikutnya adalah penyedia RSS atau penyimpanan di server cloud seperti www.soundcloud.com.

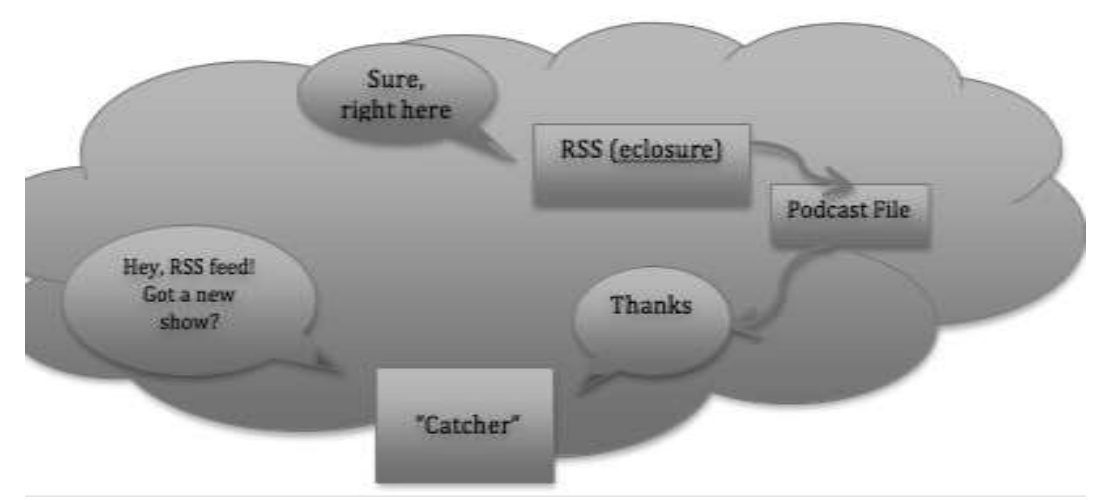

Sumber: Geoghegan dan Klass (2007)

Gambar 1. Mekanisme Distribusi Podcast

\section{Metode}

Makalah ini merupakan hasil penelitian kepustakaan dengan pendekatan kualitatif, 
terkait konten audio podcast dan potensi pengembangannya di Indonesia. Sumber data diperoleh melalui penelusuran dalam jaringan (daring) melalui berbagai situs daring penyedia layanan podcast, serta berbagai penelitian terdahulu dalam bentuk jurnal, laporan penelitian, maupun buku, serta kajian akademik dalam bentuk jurnal maupun buku; buku bahan ajar dan buku lainnya. Penelusuran berbagai sumber daring pada beberapa situs penyedia konten podcast audio juga diperdalam dengan analisis konten podcast audio.

\section{Hasil dan Pembahasan}

\section{Perkembangan Podcast Audio}

Podcast audio telah berkembang sejak pertama kali muncul di tahun 2005. Saat itu Apple menambahkan materi podcast pada iTunes dengan tema-tema terbatas. Seiring waktu, materi podcast semakin berkembang dan beragam. Kemasannya dapat berupa sandiwara/drama, dialog/talkshow, monolog dan feature/documenter. Isinya terentang dari tema-tema berkaitan sejarah, ilmu pengetahuan, politik dan banyak lagi. Bahkan menurut www.time.com, beberapa program podcast dapat menyamai popularitas serial drama televisi.

Di Indonesia, bentuk pesan podcast audio belum populer bahkan gambaran tentang keberadaan dan penggunaannya juga sangat minim. Berbeda keadaannya dengan di Amerika Serikat, daratan Eropa atau Australia dimana jumlah pengakses podcast terbilang cukup signifikan. Rilis terbaru 'State of the News Media 2016', PEW Research Center menyebutkan produk-produk podcast telah menyentuh setidaknya $36 \%$ warga Amerika. Meski angka ini dinilai kecil, namun program dan kependengaran podcast menunjukkan tren positif di tahun 2015. Bahkan menurut survey lembaga riset Edison, jumlah orang Amerika yang pernah mendengar podcast bertambah sampai 36\% dibanding tahun 2008. Pada awalnya mereka mengakses materi podcast melalui komputer jinjing atau komputer meja. Belakangan, piranti komunikasi bergerak seperti smartphone dan tablet menjadi pilihan untuk mengunduh dan mendengarkan materi podcast. Hingga kini dapat dikatakan 1 dari 3 warga Amerika Serikat pernah mendengarkan podcast (Grafik 4.).

\section{Podcast Audio di Indonesia}

Meski belum cukup populer di Indonesia, podcast audio produksi 'lokal' semakin marak di internet. Situs radio siaran konvensional selain berisi teks dan gambar serta siaran live streaming, juga menyediakan ragam pilihan konten audio di kanal podcastnya. Situs Kantor Berita Radio $68 H$, www.kbrid, menampilkan berita dalam format teks dan audio. Pada kanal Audio, pengakses dapat memutar atau mengunduh konten yang tersedia dalam format podcast audio yang terhubung dengan akun media tersebut di www.soundcloud.com. Situs www.bbc.co.uk telah lama menyediakan konten audio yang tersimpan di dalam kanal podcastnya. Variasi konten audio di situs lembaga penyiaran publik Inggris ini sangat beragam. Selain dokumenter audio dan wawancara, situs ini juga menyediakan podcast audio pelajaran bahasa Inggris yang 
kreatif dan menarik.

\section{Grafik 4.}

Rasio Warga Amerika Pendengar Podcast

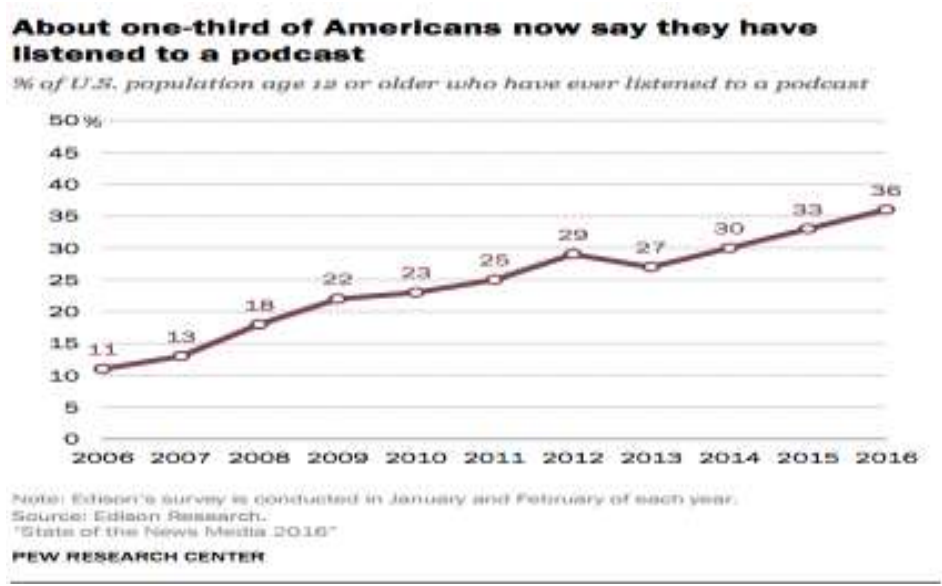

Jika berselancar di www.soundcloud.com kita dapat menemukan sejumlah materi podcast audio produksi orang Indonesia. Diantaranya akun bertajuk Subjective milik Iqbal Hariadi. Sesuai namanya, kanal menjadi tempat Iqbal berbagi pendapat pribadinya tentang beragam persoalan. Di dalam salah satu konten, Iqbal bercerita tentang latar dirinya sebagai seorang blogger yang berniat memiliki kanal youtube sendiri. Namun ia menyadari memproduksi video untuk diunggah di youtube membutuhkan kemampuan teknis tertentu, peralatan khusus, dan kuota internet cukup besar. Pilihannya kemudian jatuh pada format audio yang lebih sederhana dan murah. Iqbal ingin memberikan alternatif konten bagi khalayak yang kurang puas dengan media arus utama. Melalui akunnya tersebut Ia ingin membangun percakapan mengenai hal-hal penting yang tidak terakomodasi di media arus utama.

Dalam jangka 1 tahun, akun podcast Iqbal Hariadi memiliki 937 pengikut dengan 26 track konten. Rata-rata setiap track diputar diatas 500 kali. Jika diperhatikan, topik-topik tertentu bahkan bisa mencapai ribuan kali pemutaran, seperti topik 'salah jurusan', 'berburu beasiswa' yang mencapai 3500-an lebih. Topik-topik lain seputar kegalauan kaum muda, ide dan motivasi, rata-rata bisa mencapai sekitar 2000 kali pemutaran.

Pegiat podcast audio bernama Adriano Qalbi telah aktif berpodcast sejak tahun 2015 lewat akun bernama Podcast Awal Minggu. Saat diakses bulan Februari 2017, akun ini memiliki hampir 2500 pengikut dengan 107 tracks berdurasi rata-rata 1 jam ke atas. Obrolan Adriano dan istrinya tentang pasangan yang suka pamer di sosmed diputar sampai hampir 5500 kali.

Podcast audio juga dimanfaatkan oleh selebritas Indonesia. Diantaranya adalah Joshua Suherman dengan akun podcast bertajuk Teman Berkemudi. Akun ini memang belum seramai dua akun diatas. Namun, untuk sebuah akun yang berumur baru 1 bulan dengan hanya 3 tracks (akses 20 Februari 2017), pengunjung akun ini sudah cukup 
ramai. Setidaknya track rekaman 'curhatan' mengenai keseharian Joshua telah diputar 1000 kali lebih.

Podcast audio juga dimanfaatkan untuk tujuan pendidikan dan pemberdayaan masyarakat. Di situs www.indonesiabercerita.org tersedia cerita dan dongeng anak dalam format audio yang dapat diunduh secara gratis. Situs ini juga juga mengembangkan kolaborasi antar warga dengan memberikan kesempatan kepada warga untuk mengunggah karya podcast audio mereka.

\section{Pengelolaan dan Kriteria Kesuksesan Podcast}

Pengelolaan materi podcast audio pada dasarnya sama dengan ragam bentuk media lain. Dalam bukunya “Expert Podcasting for Dummies", Morris, Terra, dan Williams (2008) menekankan pentingnya perencanaan dengan menentukan topik yang sesuai. Idealnya, pegiat podcast audio menggarap topik yang berada dalam bidang minat dan kemampuannya. Di samping itu, perlu mempertimbangkan ketersediaan sumber daya untuk menggarap topik-topik yang dipilih. Misalnya, beberapa situs online perguruan tinggi menyediakan materi podcast berisi topik ilmiah dari para ahli atau pakar yang ada di perguruan tinggi tersebut. Setelah menentukan topik, perhitungkan juga potensi khalayak atau pendengar yang membutuhkan dan atau berminat dengan topik yang direncanakan. Semakin besar potensi pendengar semakin layak rencana produksi dilanjutkan.

Pertimbangan lain adalah sejauh mana topik tersebut bisa digali lebih dalam atau lebih luas dikembangkan. Hal ini memudahkan pengelola untuk memproyeksikan topik-topik turunan untuk diproduksi lebih lanjut sehingga program podcast tersebut 'berumur panjang'. Selanjutnya adalah memikirkan 'positioning' bagi produk podcast yang akan diproduksi. Dengan semakin maraknya keberadaan materi podcast di jagat maya, sebaiknya dilakukan pemetaan sebagai dasar menentukan 'unique selling point' atau 'value' yang hendak ditawarkan.

Langkah berikutnya dari rencana pengelolaan adalah memetakan kebutuhan dan ketersediaan sumber daya manusia. Proses produksi dapat berjalan dengan baik jika setiap orang menjalankan tugasnya dalam mata rantai produksi dengan optimal. Faktor sarana dan prasarana menjadi sebuah keharusan karena proses produksi materi audio sangat tergantung dari ketersediaan alat seperti microphone dan atau alat perekam. Secara teknis, kualitas materi audio sangat bergantung pada alat-alat dasar tersebut dan karenanya sangat penting untuk memastikan kehandalan dan kualitasnya.

Ada baiknya melakukan benchmark dengan produk-produk podcast audio yang telah sukses sebelumnya. Situs agregator materi podcast yang berpusat di Amerika Serikat, www.podbay.fm menyusun ranking 100 podcast terbaik. Program podcast In The Dark berada di urutan pertama disusul TED Radio HOUR yang diproduksi National Public Radio (NPR). Urutan ketiga ditempati program dari penulis ternama Malcolm Gladwell bertajuk Revisionist History. 


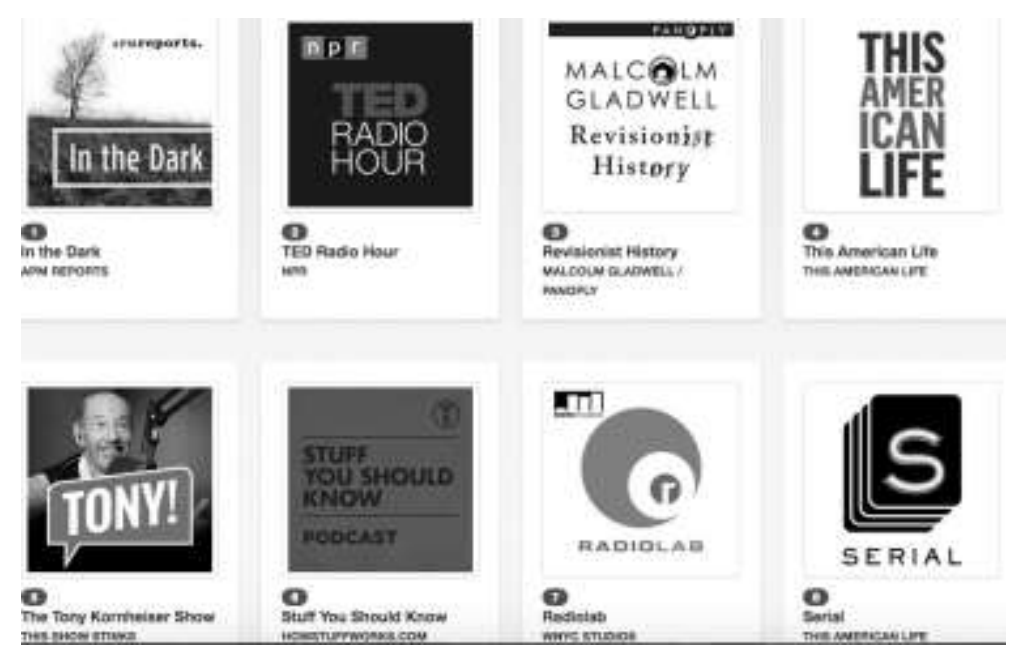

Gambar 1.

Ranking teratas dalam daftar 100 Podcast Terpopuler versi www.podbay.fm

Pada bulan Maret 2016, Tech Insider merilis daftar podcast terbaik di dunia versi media tersebut. Di dalam situsnya www.techinsider.io dinyatakan bahwa podcast audio merupakan sumber yang tepat untuk cerita, wawancara, dan karya jurnalistik. Podcast yang umumnya berdurasi dari beberapa menit sampai 1 jam tersebut, menyediakan ruang kreasi bagi para kreatornya untuk bicara langsung pada pendengar, bebas dari pengalihan perhatian, dan menyediakan cara baru mengisi ruang dengar para komuter. Materi podcast yang termasuk di dalam daftar tersebut mencakup wilayah minat yang luas, seperti: teknologi, budaya, ilmu pengetahuan, dan inovasi. Program Codebreaker menurut Tech Insider merupakan cara bercerita tentang teknologi yang cerdas dengan mempertanyakan dampak teknologi pada dunia kita. Ada lagi program bernama Surprisingly Awesome, sebuah program dari Gimlet yang memadukan secara memikat topik-topik terkait ilmu pengetahuan dan teknologi, dalam kemasan layaknya debat di kedai minum. Pemilihan materi-materi podcast tersebut menekankan kriteria keseimbangan antara nilai informasi dan hiburan.

Situs www.esquire.co.uk merekomendasi 25 podcast untuk diunduh. Kriteria podcast yang patut direkomendasikan, menurut situs majalah pria tersebut terutama pada sifat isinya yang dapat menjadi 'makanan' sehat otak dan menyegarkan perjalanan para komuter. Di dalam daftar itu, posisi pertama ditempati program Sodajerker On Songwriting, sebuah program musik yang dikemas menarik lewat kepiawaian duo Simon Barber dan Brian O'Connor meramu cerita sambil menulis musik bersama. Ada lagi cerita mengenai hal-hal yang tidak kita ketahui tapi patut 'diulik' lalu membuat pendengarnya berujar, "kok bisa siiih ....". Portal www.esquire.com memilih sebuah program talkshow yang mengangkat beragam topik dari dunia hiburan menggunakan perspektif budaya pop dalam program Pop Culture Happy Hour From NPR. Berikutnya ada The Slate Political Gabfest sebuah program obrolan politik yang dikemas mendalam namun dibumbui humor berkualitas layaknya membicarakan isu politik di pesta-pesta kebun atau reuni. Ada lagi podcast Oxford 
Biography yang disadur dari hasil penelitian para ahli sejarah Oxford Dictionary of National Biography apa adanya dan tanpa bias.

Time menurunkan daftar 10 podcast terpopuler sepanjang tahun 2015 berdasarkan tingkat akses, unduh maupun streaming dari iTunes. Data yang didapat dari Apple itu menempatkan program NPR Fresh Air di urutan pertama. Program berisikan obrolan mengenai budaya populer tersebut dipandu Terry Gross. Tempat kedua diduduki Serial dari kreator This American Life dan dibacakan oleh seorang jurnalis bernama Sarah Koenig. Di dalam daftar tersebut juga terdapat program Stuff You Should Know yang berisi penjelasan bagaimana sesuatu bekerja, semisal topik tentang penyakit rumit atau cerita perjalanan menyelami diri orang terkenal. Ada juga program bincang keuangan dan investasi seperti The Dave Ramsey Show dan Planet Money.

Berikutnya adalah rekomendasi 50 karya podcast yang wajib didengarkan versi www.theguardian.com pada bulan Mei 2016. Rentang topik di dalam daftar yang dikeluarkan situs berita terkenal itu sangat variatif, dari cerita kriminal sampai komedi bahkan beberapa kemasan terkesan unik, nyentrik dan provokatif. www.theguardian.com juga membeberkan materi-materi podcast mereka sendiri dalam beragam topik. Diantaranya cerita mengenai latar kebijakan redaksi dari berita atau karya jurnalistik yang telah dipublikasikan.

Bila digarisbawahi, program podcast yang direkomendasikan umumnya memiliki kriteria sebagai berikut:

1. Ragam topik relevan

2. Dikemas santai dengan nuansa humor

3. Menggunakan pendekatan bintang atau orang terkenal

4. Menghibur, menggelitik dan akrab

5. Unik/tidak biasa

6. Sederhana

7. Percakapan

8. D1l

\section{Menakar Potensi Podcast Audio}

Sebagaimana halnya bentuk media yang lain, podcast audio dapat memainkan peran sebagai sumber informasi, edukasi dan hiburan bagi khalayak tertentu. Karakter audio yang melekat pada podcast jika dikelola dengan baik setidaknya memiliki pangsa pasar kaum auditori yang menurut sebuah penelitian berjumlah sekitar $30 \%$ dari total populasi. Potensi pendengar lain adalah khalayak yang karena faktor tertentu hanya dapat mengandalkan indera pendengaran untuk mengakses pesan. Para komuter juga dapat diperhitungkan sebagai khalayak potensial mengingat jumlahnya kian meningkat. Dalam perjalanan pulang dan pergi beraktivitas, para komuter biasanya cenderung memilih merintang waktu dengan mendengarkan konten audio.

Budaya tutur orang Indonesia merupakan salah satu sinyalemen potensi pengembangan podcast audio (Rusdi, 2012). Selain itu menurutnya, podcast audio dapat menambal kekurangan radio siaran yang selintas selain juga berfungsi sebagai 
penyimpanan produk-produk audio (dokumentasi). Menurut Geoghegan dan Klass, potensi podcast terletak pada keunggulannya; dapat diakses secara otomatis, mudah dan kontrol ada di tangan konsumen, dapat dibawa-bawa, dan selalu tersedia (2007).

Usaha serius sangat dibutuhkan untuk menggali potensi bisnis podcast audio. Ternyata, pertumbuhan podcast belum diimbangi peningkatan keuntungan signifikan. Para pengelola podcast audio harus berusaha keras untuk menarik pengiklan karena sumber pemasukan ini sepertinya belum tertarik. Sebagian podcast diproduksi dan disebarluaskan dengan mengandalkan dukungan dana dari para donatur, baik individual maupuan kelembagaan seperti dilansir dalam laporan tahunan Tow Center for Digital Journalism.

Minimnya pengiklan menurut Pew Research, di antaranya disebabkan oleh minimnya alat dan metode pengukuran. Selama ini angka mengenai tingkat kependengaran podcast didapat melalui data jumlah materi yang diunduh. Padahal, jumlah tersebut belum menunjukkan tingkat kependengaran karena bisa jadi materi tersebut hanya diunduh, tidak didengarkan, baik sebagian maupun keseluruhannya. Lembaga riset Nielsen mengendus kebutuhan hasil pengukuran akses materi podcast dan potensi yang dikandungnya. Bulan April 2016, perusahaan riset ini mengumumkan akan mulai mengukur audio on-demand dan podcast sebagai bagian dari layanan digital audio ratings.

Di tengah ketidakpastian potensi bisnis podcast, beberapa pihak malah terlihat mulai mengembangkan unit produksi konten podcast audio mereka. Bulan Mei tahun 2015, The New York Times membentuk tim produksi podcast bermuatan program berita dan opini. The Wall Street Journal menyusul melakukan hal sama di bulan Desember 2015. Beberapa startup media seperti Slate, Buzzfeed, Radiotopia, Gimlet dan Goat Rodeo turut meramaikan jagat maya dengan materi podcast berisi berbagai ide program kreatif.

Akan halnya di Indonesia, lebih besar lagi usaha yang dibutuhkan untuk mengkaji dan menggali potensi podcast audio. Sejauh ini belum banyak penelitian seputar tren podcast audio di Indonesia. Tidak dipungkiri, aktivitas mengunduh materi audio sangat marak, khususnya untuk materi audio bermuatan hiburan seperti lagu. Namun podcast audio bermuatan informasi dan berita maupun edukasi belum muncul ke permukaan. Untuk sementara diasumsikan, podcast audio di Indonesia belum menggejala karena masih minimnya jumlah podcast yang ada dengan tawaran 'value' yang juga belum jelas. Perlu usaha berkesinambungan untuk membangun budaya 'berpodcast' di Indonesia di antaranya adalah dengan menyajikan materi podcast berkualitas untuk berbagai kegunaan. Selain itu yang tidak kalah penting adalah promosi untuk memopulerkan podcast audio di tanah air.

\section{Simpulan}

Podcast audio cukup populer di Amerika Serikat dan beberapa negara di Eropa. Pengakses podcast audio disana memiliki pilihan konten yang semakin beragam, menarik, dan berkualitas. Perkembangan podcast audio di kedua kawasan tersebut 
ditunjang promosi lintas media dan tidak kalah penting sejumlah riset yang memberikan gambaran mengenai tren perkembangan podcast audio dari berbagai aspeknya.

Di Tanah Air, podcast audio belum begitu populer. Penelitian terkait mengenai podcast audio juga masih sangat minim. Meski demikian, beberapa tahun belakangan, beragam produk podcast audio lokal mulai meramaikan jagat maya dan terbilang cukup sukses menarik pendengar. Sebagian produk podcast audio tersebut diproduksi dan didistribusikan oleh beberapa situs online radio dan para audio blogger. Podcast audio berpotensi dikembangkan di Tanah Air mengingat kentalnya budaya tutur masyarakat Indonesia. Selain itu, akses terhadap internet semakin mudah dan murah sehingga membuat produk podcast audio di internet lebih terjangkau. Podcast audio dapat menambal kekurangan radio siaran yang selintas selain juga berfungsi sebagai penyimpanan produk-produk audio (dokumentasi).

Potensi podcast terletak pada keunggulannya; dapat diakses secara otomatis, mudah dan kontrol ada di tangan konsumen, dapat dibawa-bawa, dan selalu tersedia. Formula kesuksesan konten podcast audio diantaranya terletak pada pengemasan yang ringan dan menarik dengan tawaran 'nilai' yang jelas bagi calon pengakses. Produksi podcast audio seyogyanya mempertimbangkan dan mendalami kekuatan serta karakteristik format audio sebagai medium komunikasi manusia. Berikutnya adalah selalu mengikuti perubahan perilaku dan kebiasaan bermedia masyarakat terutama dalam mengkonsumsi format audio.

\section{Daftar Pustaka}

Dubber, A. (2013). Radio in the Digital Age. UK: Polity Press.

Fidler, R. (2003). Mediamorfosis. Bentang Budaya.

Geller, V. (2011). Beyond Powerful Radio. Elsevier.

Geoghegan, Michael W., Klass, Dan. (2007). Podcast Solutions: The Complete Guide to Audio and Video Podcasting. USA: Friendsof.

McQuail, D. (2011), Teori Komunikasi Massa. Jakarta: Salemba humanika.

Morris, Tee., Terra, Evo., Williams, Ryan. (2008). Expert Podcasting Practices for Dummies. USA: Wiley Publishing, Inc

Prayudha, H. (2005). Radio: Suatu Pengantar untuk Wacana dan Praktik Penyiaran. Malang: Bayumedia Publishing

Rusdi, Farid. (2012). Podcast sebagai Industri Kreatif. Proceeding Seminar Nasional, Inovasi, dan Teknologi BSI hal 91-94.

http://iqbalhariadi.com/post/135898404260/adriano-qalbi-podcast-subjective diakses 12 Februari 2017

http://journal.tarumanagara.ac.id/index.php/kidFik/article/view/1252

http://www.digitalnewsreport.org/publications/2016/predictions-2016/ diakses 5 Januari 2017 
104 | Kajian Jurnalisme Volume 1 Nomor 1 Tahun 2017 - hal 90-104

http://www.pewresearch.org/topics/state-of-the-news-media, diakses 20 Desember 2016 www.theguardian.com. The 50 Best podcasts of 2016, diakses 20 Oktober 2016 www.techinsider.io. The Best Podcast in The World, diakses 20 Oktober 2016 www.time.com, The 10 Most Popular podcast of 2015, diakses 20 Desember 2016 http://www.webaward.org/winners_detail.asp?yr=all\&award_level=best\&category=Radio\#. Vvu4q2pJnIU, diakses Rabu 30 Maret 2016 http://www.webaward.org/winners_detail.asp?yr=all\&award_level=best\&category=Radio\#. Vvu4q2pJnIU, diakses Rabu 30 Maret 2016 